\title{
Mössbauer study of iron gall inks on historical documents
}

\author{
A. Lerf ${ }^{1 *}\left(\mathbb{D}\right.$, F. E. Wagner ${ }^{2}$, M. Dreher ${ }^{3}$, T. Espejo $^{4}$ and J.-L. Pérez-Rodríguez ${ }^{5}$
}

\begin{abstract}
Iron gall ink was used in the Western world as a permanent writing material already in late Roman times and throughout the Middle Ages, until it became obsolete in the twentieth century. There is much interest in experimental methods to determine the state of the ink and its degradation products on historical documents. Mössbauer spectroscopy with ${ }^{57} \mathrm{Fe}$ is such a method, and it has the particular advantage to be sensitive to the chemical bonding of iron, but this method has only rarely been applied to historical documents. In this paper we present Mössbauer data for two damaged documents from a Library in Granada and a handwritten German book from the eighteenth century. In addition to the inked parts of the manuscripts, ink-free parts were studied to determine the amount and chemical state of the iron in the papers. These new results are discussed in the context of previously published Mössbauer data. In one of the investigated documents $\mathrm{Fe}(\mathrm{II})$-oxalate, $\mathrm{FeC}_{2} \mathrm{O}_{4} \cdot 2 \mathrm{H}_{2} \mathrm{O}$, was observed. The assignment of the various $\mathrm{Fe}^{3+}$ sites in the different documents is rather difficult and often there is a superposition of various species. Known forms of iron gallate are definitely not present on the inked papers. The observed ferric species can be remains of $\mathrm{Fe}^{3+}$ polyphenol complexes of the ink, complexes of $\mathrm{Fe}^{3+}$ with degradation products of the cellulose of the paper or gum arabic, or very small iron oxide or hydroxide nanoparticles.
\end{abstract}

Keywords: Mössbauer spectroscopy, Iron gall inks, IGI, Historical documents, Fe(II)-oxalate, Jarosite

\section{Introduction}

The use of iron gall inks probably came from Egypt to Palestine in the third century A.D. and from there to Europe [1-4]. Such inks were already used in late Roman times [2-6] and became an important writing material in the Western world in the Middle Ages and during modern times until they became obsolete in the twentieth century $[2,3,7]$. Documents written with iron gall inks often suffer from severe degradation, depending on the quality of the writing supports and on the composition of the ink $[3,8,9]$. The chemical nature of the color-carrying component and the processes of degradation are still a matter of debate [9]. In the past decades, there has been a growing interest in addressing these

\footnotetext{
*Correspondence: anton.lerf@t-online.de

1 Walther-Meißner-Institute, Bavarian Academy of Sciences,

Garching 85748, Germany

Full list of author information is available at the end of the article
}

questions by physical methods. Proton induced X-ray spectroscopy (PIXE) [10-12] and X-ray fluorescence spectroscopy (XRF) [5, 13-17] allow a quantitative analysis of the various elements in written documents on a length scale of 0.5 to $3 \mathrm{~mm}$. Attenuated total reflectance (ATR) Fourier transformed infrared (FTIR) [13-15] and micro-Raman spectroscopy $[5,13-15,18,19]$ give information on the chemical nature of the organic compounds involved in ink formation and their degradation products. EXAFS studies of inks and inked papers might also be used to obtain information on the bonding of the iron [20]. Micro-XANES (X-ray absorption near edge spectroscopy) [17, 21-23] and Mössbauer spectroscopy [20, 24-26] with ${ }^{57} \mathrm{Fe}$ are sensitive to the chemical state of the iron, which is thought to be the essential component of the color-carrying unit and most likely an important player in the degradation processes. Whereas XANES monitors mainly the $\mathrm{Fe}^{2+} / \mathrm{Fe}^{3+}$ ratio, Mössbauer spectroscopy additionally allows more detailed conclusions

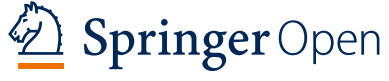

(c) The Author(s) 2021 corrected publication 2021 This article is licensed under a Creative Commons Attribution 4.0 International License, which permits use, sharing, adaptation, distribution and reproduction in any medium or format, as long as you give appropriate credit to the original author(s) and the source, provide a link to the Creative Commons licence, and indicate if changes were made. The images or other third party material in this article are included in the article's Creative Commons licence, unless indicated otherwise in a credit line to the material. If material is not included in the article's Creative Commons licence and your intended use is not permitted by statutory regulation or exceeds the permitted use, you will need to obtain permission directly from the copyright holder. To view a copy of this licence, visit http://creativecommons.org/licenses/by/4.0/. The Creative Commons Public Domain Dedication waiver (http://creativeco mmons.org/publicdomain/zero/1.0/) applies to the data made available in this article, unless otherwise stated in a credit line to the data. 
on the chemical state of the iron on the basis of the isomer shift and the electric quadrupole splitting of the Mössbauer resonance [27], and it allows the identification of magnetically ordered phases like iron oxides or hydroxides [28]. The identification of magnetic hyperfine interactions often requires measurements at liquid helium temperature. Mössbauer measurements at $4.2 \mathrm{~K}$ also allow the unambiguous identification of iron compounds with gallic acid [29, 30], which are important constituents of ferrogallic inks. Mössbauer spectroscopy requires several hundred milligrams of paper to make absorbers with a thickness of several hundred milligrams per square centimeter. This material has to be removed from the documents. If one wants to avoid this, one can use folded documents or pass the gamma rays through several pages of an opened book, at least for measurements at ambient temperature. At low temperatures, typically in a liquid $\mathrm{He}$ cryostat, this will not be possible.

Up to now only a few documents have been investigated by Mössbauer spectroscopy: Ancient manuscripts studied by Mössbauer spectroscopy are a French document from the fifteenth century [24, 25], a Syriac document from the twelfth century [24], and three documents from the national library of Poland [20]. More recently, Mössbauer spectroscopy also revealed the presence of traces of iron in the paper of old documents [26].

In addition to these studies of old manuscripts, there are several Mössbauer studies on iron-polyphenol complexes and of laboratory-made inks as bulk materials and on writing supports [22, 29-32]. Compounds formed by polyphenols with iron salts and metallic iron have also been studied by Mössbauer spectroscopy under the aspect of iron corrosion and its inhibition by polyphenols [33-36] and of biochemistry [37]. These studies show that the room temperature Mössbauer spectra of compounds formed by iron with polyphenols exhibit mainly an electric quadrupole doublet of trivalent iron with splittings between about 0.7 and $1.1 \mathrm{~mm} / \mathrm{s}$, which are typical for high-spin ferric iron [27] and do not readily allow an identification of specific compounds [38]. Only two compounds of iron with gallic acid have been studied in some detail. One of these is a crystalline Fe(III) gallate $[39,40]$ with a quadrupole splitting of about $0.5 \mathrm{~mm} / \mathrm{s}$ at ambient temperature. At liquid helium temperature, it is magnetically ordered and exhibits a magnetically split spectrum with a hyperfine field of about $41.5 \mathrm{~T}$ [29]. The other Fe(III) gallate is amorphous or microcrystalline [29, 31]. Its room temperature Mössbauer spectrum is a broad quadrupole doublet with a mean splitting of about $1.1 \mathrm{~mm} / \mathrm{s}$ arising from several different iron environments. This gallate is also magnetically ordered at $4.2 \mathrm{~K}$, exhibiting a Mössbauer spectrum that again shows the presence of several different iron environments with hyperfine fields between 46 and $48 \mathrm{~T}$ [29]. The latter iron gallate is supposed to play a major role in ferrogallic inks [31]. If present in written manuscripts, it can be identified unambiguously by its $4.2 \mathrm{~K}$ Mössbauer spectrum.

In the present work Mössbauer data are presented for two document fragments from the University Library in Granada (Spain) and for a German hand-written cookbook from the eighteenth century. Measurements were performed at both ambient temperature and at $4.2 \mathrm{~K}$. Care was also taken to study the paper on which the documents were written for traces of iron. The new results are discussed in the context of the previous Mössbauer data. In one of the studied Spanish documents Fe(II)oxalate $\left(\mathrm{FeC}_{2} \mathrm{O}_{4} \cdot 2 \mathrm{H}_{2} \mathrm{O}\right)$ was observed. Oxalic acid may be a deterioration product of the ink, the gum arabic or the cellulose. The assignment of the various $\mathrm{Fe}^{3+}$ sites observed in the different historical documents is not straightforward. Iron oxides or oxy-hydroxides can be identified by Mössbauer measurements at liquid helium temperature, where they are magnetically ordered and hence exhibit a magnetic hyperfine splitting [28]. Species that are still paramagnetic at $4.2 \mathrm{~K}$, however, are difficult to identify. This is particularly true for ferric iron, for which in most cases neither the isomer shift nor the electric quadrupole splitting differ much for different compounds [27, 38]. It is therefore difficult to distinguish whether such species are deterioration products of iron polyphenol complexes of the ink, iron-cellulose adducts or reaction products of iron with a binder like gum arabic in the ink.

\section{Experiments and methods}

\section{Historic documents and absorber preparation}

Two of the studied documents were parts of single pages provided by T. Espejo, Granada. Both were endpapers of a book printed in Rome in 1715 and were removed from that book in the course of a recent restoration carried out in Granada. The manuscript shown in Fig. 1a is written in a chancery hand called letra procesal. This type of writing was used in chanceries in Spain in the fifteenth and sixteenth century. We will call this specimen Chancery $M S$ in the following. The writing on it is rather irregular, indicating that it was written as a calligraphic exercise. The writing is grayish and faded, and the paper turned out to be quite brittle. After removal of the ink-free rim, the remainder $(840 \mathrm{mg})$ was therefore crushed and put into a Lucite absorber holder. The rim $(310 \mathrm{mg})$ was also put into an absorber holder for separate measurements of the paper alone.

The manuscript shown in Fig. 1b consists of rather large single letters in Latin script, probably also from a calligraphic exercise, and will be called Latin MS. In this case it was possible to cut the deep black letters 

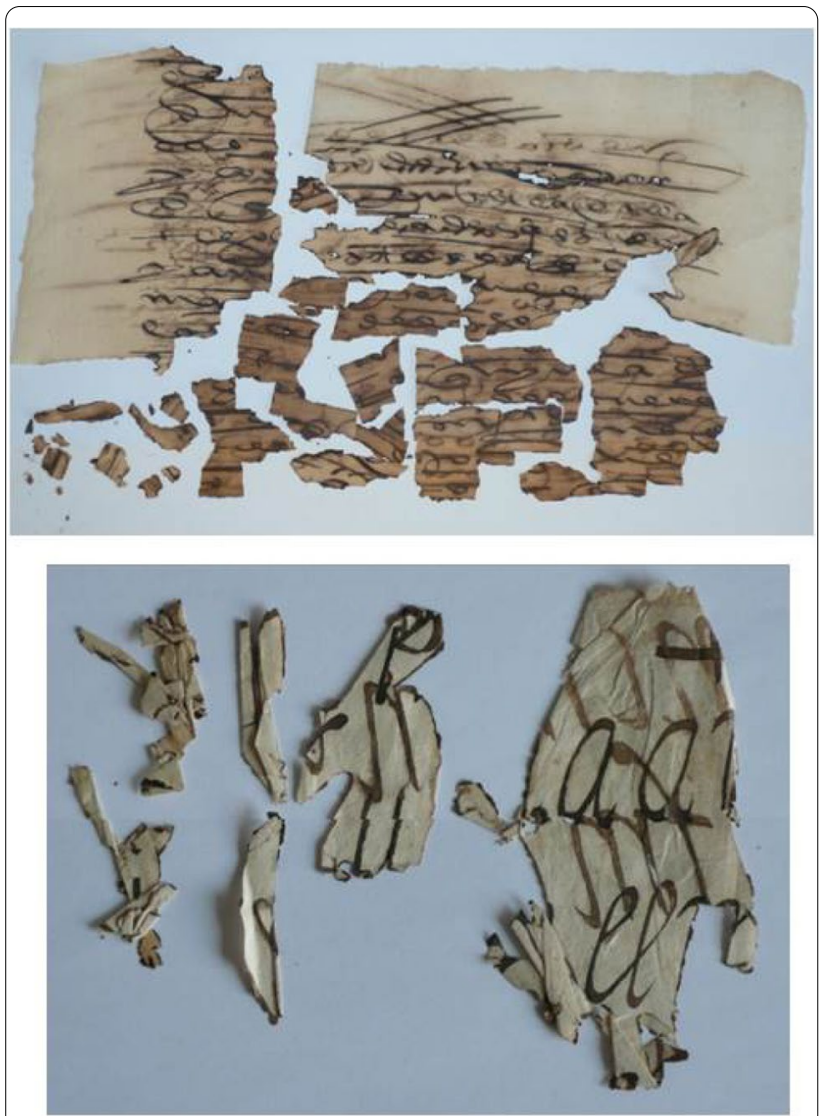

Fig. 1 Photographs of the two fragments from the Granada Library, called the Chancery MS (top) and the Latin MS (bottom)

out of the manuscript to be studied separately from the parts that did not contain any ink. This would be very difficult for smaller letters, but it is certainly an advantage to study the inked parts practically without paper without ink. Both the ink-covered part (172 mg) and the remainder $(436 \mathrm{mg}$ ) were put into Lucite sample holders for Mössbauer measurements at room temperature and $4.2 \mathrm{~K}$. The thicknesses of the individual absorbers are given in Table 1.

The third historic document we investigated is the handwritten cooking book of a lady, Anna Maria Widenplazerin, from the year 1783 (private property of F.E. Wagner, Fig. 2). This book is quite well preserved, but the writing is rather faint and brownish. All pages have writing on both sides and are rather densely written. For a first Mössbauer measurement at room temperature, the $14.4 \mathrm{keV}$ gamma rays were passed through 53 pages of the opened book, which yielded a good Mössbauer transmission spectrum within a few days. For a low temperature measurement we had to remove a page from the book $\left(16 \times 19 \mathrm{~cm}^{2}\right.$; ca. $\left.2 \mathrm{~g}\right)$. This was cut it into squares of about $15 \times 15 \mathrm{~mm}^{2}$. Of these, 121 were stacked to make a Mössbauer absorber, which was measured at both $4.2 \mathrm{~K}$ and room temperature. In order to check whether there is any iron in the paper itself, we also removed an empty page from the book and cut it into squares, from which a Mössbauer absorber consisting of 88 layers was made and measured at room temperature and $4.2 \mathrm{~K}$. All absorber thicknesses are given in Table 1.

For comparison with components in the Mössbauer spectra of the document samples, we measured Mössbauer spectra of $\mathrm{Fe}(\mathrm{II})$-oxalate and of two samples of jarosite. $\mathrm{Fe}(\mathrm{II})$-oxalate $\left(\mathrm{FeC}_{2} \mathrm{O}_{4} \cdot 2 \mathrm{H}_{2} \mathrm{O}\right)$ was obtained from Alpha Aesar Chemicals. Potassium jarosite $\left(\mathrm{KFe}_{3}\left(\mathrm{SO}_{4}\right)_{2}(\mathrm{OH})_{6}\right)$ was prepared as described by Driscoll and Leintz [41] by reacting a solution of $\mathrm{FeSO}_{4} \cdot 7 \mathrm{H}_{2} \mathrm{O}$ and $\mathrm{KOH}$ at $140{ }^{\circ} \mathrm{C}$ in a closed vessel for about $5 \mathrm{~h}$. Hydronium jarosite was obtained by letting a hydrous solution of $\mathrm{FeSO}_{4}{ }^{-7} 7 \mathrm{H}_{2} \mathrm{O}$ dry in a flat dish at about $20{ }^{\circ} \mathrm{C}$ within a few weeks. Both jarosites were identified by X-ray diffraction.

Table 1 Total areas of the Mössbauer spectra of the studied specimens

\begin{tabular}{|c|c|c|c|c|c|c|}
\hline Document & $\begin{array}{l}\text { Absorber } \\
\text { thickness } \mathrm{mg} / \mathrm{cm}^{2}\end{array}$ & Total area at RT & $\begin{array}{l}\text { Iron content } \\
\mathrm{mg} / \mathrm{g}\end{array}$ & Total area at $4.2 \mathrm{~K}$ & $\begin{array}{l}\text { Iron content } \\
\mathrm{mg} / \mathrm{g}\end{array}$ & Surface $\mathrm{pH}$ \\
\hline Chancery MS total & 545 & 0.038 & 3.6 & 0.112 & 6.0 & $4.2-3.9$ \\
\hline Chancery MS paper only & 240 & 0.0031 & 0.44 & 0.0029 & 0.50 & 4.8 \\
\hline Latin MS paper with ink & 219 & 0.037 & 8.8 & 0.11 & 21 & 4.8 \\
\hline Latin MS paper only & 386 & 0.0081 & 1.1 & 0.012 & 1.2 & 5.3 \\
\hline Cookbook total 53 pages & 360 & 0.014 & 2.0 & - & - & - \\
\hline Cookbook total 121 layers & 825 & 0.016 & 1.0 & 0.037 & 1.7 & 4.9 \\
\hline Cookbook paper only 88 layers & 600 & 0.0017 & 0.15 & 0.0011 & 0.07 & 5.7 \\
\hline
\end{tabular}

The iron contents were estimated from the intensities of the Mössbauer spectra as described in the text. The smaller values for the iron contents obtained from the RT spectra compared to those from the $4.2 \mathrm{~K}$ spectra are attributed to the decrease of the Lamb-Mössbauer factor with increasing temperature. In the last column the surface $\mathrm{pH}$ values of spots with ink and, for the papers only, of spots without ink are given 

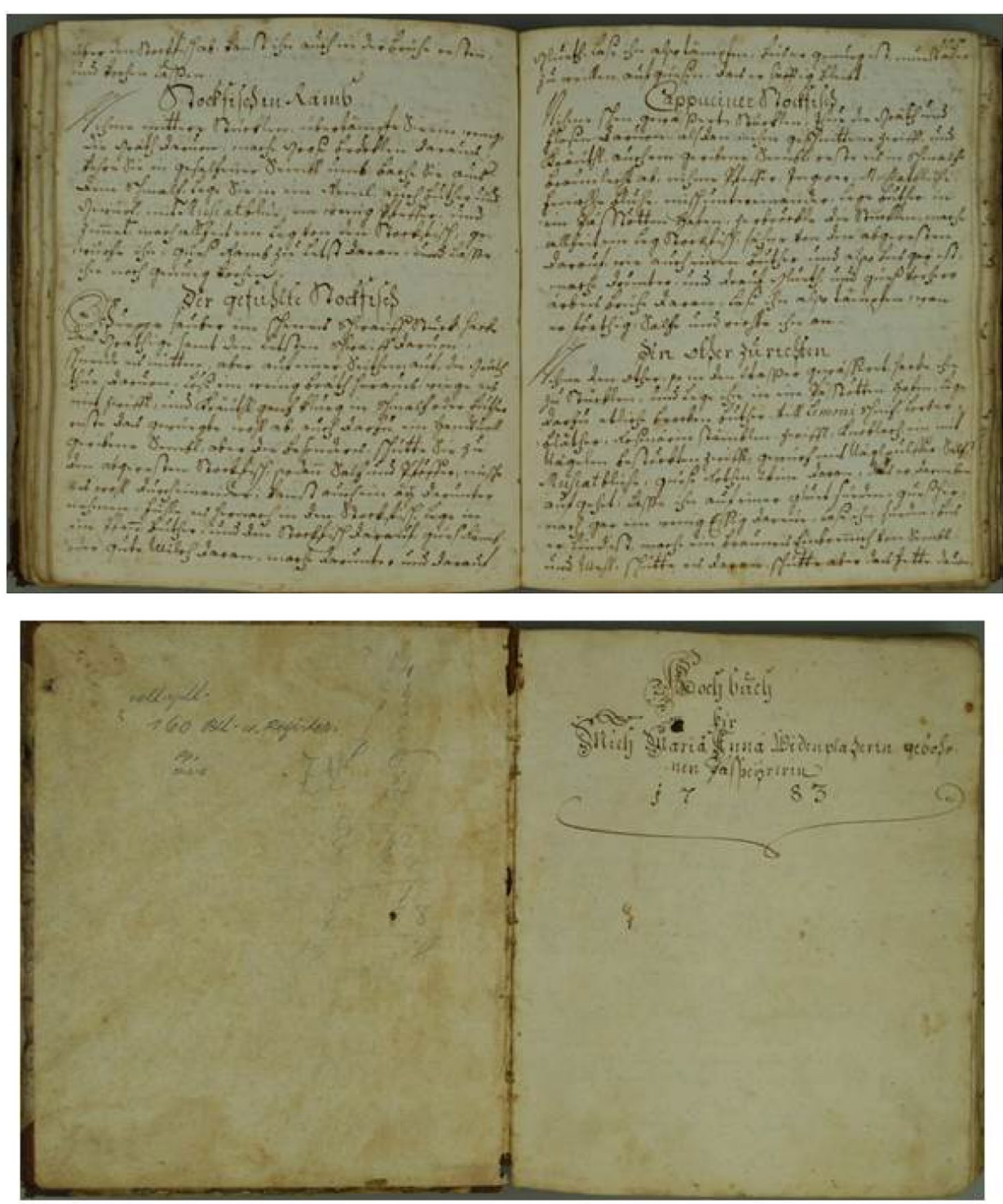

Fig. 2 Photographs of the cooking book of the Widenplazerin from the year 1783: two randomly chosen pages (top) and the front page (bottom)

\section{Methods}

The room temperature Mössbauer spectra were recorded with a conventional transmission spectrometer using a sinusoidal velocity waveform (Halder Elektronik, Germany) and a ca. $25 \mathrm{mCi}$ source of ${ }^{57} \mathrm{Co}$ in Rh. Low temperature measurements were performed in a liquid He bath cryostat with both source and absorber cooled to $4.2 \mathrm{~K}$. The $14.4 \mathrm{keV}$ gamma rays of ${ }^{57} \mathrm{Fe}$ were detected with a $\mathrm{Kr} / \mathrm{CO}_{2}$ filled proportional counter. Isomer shifts (IS) are given with respect to the source having the same temperature as the absorber and can be converted to shifts relative to $\alpha$-iron at room temperature by adding $0.11 \mathrm{~mm} / \mathrm{s}$ to the room temperature data. To the $4.2 \mathrm{~K}$ data, $0.24 \mathrm{~mm} / \mathrm{s}$ have to be added to refer them to $\alpha$-iron at room temperature, because the second order Doppler shift has to be taken into account. All spectra were least-squares fitted with superpositions of Lorentzian lines grouped into quadrupole doublets or magnetically split sextets. In a few cases, Gaussian distributions of hyperfine fields gave better fits for magnetically split patterns than sextets with Lorentzian lines. In such cases a Lorentzian width of $0.25 \mathrm{~mm} / \mathrm{s}$ was used and the distributions are described by the mean field $B$ and the variance $\sigma_{B}$ of the field distribution. The line-shapes were calculated by superimposing 40 sextet patterns with Lorentzian lines, 
different hyperfine fields and intensities appropriate for a Gaussian distribution of hyperfine fields.

Absorbers of iron(II)-oxalate $\left(\mathrm{FeC}_{2} \mathrm{O}_{4} \cdot 2 \mathrm{H}_{2} \mathrm{O}\right), 21.5 \mathrm{mg} /$ $\left.\mathrm{cm}^{2}\right)$ and potassium jarosite $\left(\mathrm{KFe}_{3}\left(\mathrm{SO}_{4}\right)_{2}(\mathrm{OH})_{6}, 16.3 \mathrm{mg} /\right.$ $\mathrm{cm}^{2}$ ) were used to measure the Lamb-Mössbauer f-factors for these compounds at 300 and $4.2 \mathrm{~K}$ by comparison of the spectral intensities with that of a metallic $\alpha-\mathrm{Fe}$ foil $\left(5.68 \mathrm{mg} / \mathrm{cm}^{2}\right)$ measured together with absorbers of the compounds in the same Mössbauer experiment. With $f(4.2 \mathrm{~K})=0.925$ and $\mathrm{f}(300 \mathrm{~K})=0.80$ for $\alpha$-Fe [42] one can then derive the f-factors of the compounds.

The surface $\mathrm{pH}$ was measured with a Mettler Toledo Seven Easy instrument and a Metrohm Nr. 6.0256.100 surface electrode at spots with and without visible ink. The measurements were carried out according to the TAPPI-protocol T 529. For the measurement the paper was placed on a flexible, hydrophobic support pad. Deionized water $(0.05 \mathrm{ml})$ was applied to the position selected for measurement. The glass electrode mounted in a support was then carefully placed on the drop of water and pressed onto the paper surface to make good contact. The measurement stopped automatically after equilibrium was reached. A visual coloring test with zinc chloride-iodide [43] confirmed that all three papers under investigation are of rag-type, probably from flax, hemp or cotton.

\section{Results and discussion}

\section{Iron contents of the samples}

The Mössbauer spectra of the studied documents are shown in Figs. 3, 4, and 5. On the left side of these Figures, the spectra of the papers with ink are shown. To make certain that these spectra really represent the traces of the ink on the papers and not merely an iron contamination of the papers themselves, we measured Mössbauer spectra of pieces of all three documents which are free from visible traces of ink. These are shown on the right side of Figs. 3, 4, and 5. All three ink-free papers contain some iron, but at least a factor of ten less than for the pieces with writing.

The fitting results of the Mössbauer spectra are summarized in Tables 1 and 2. Table 1 gives the thickness of

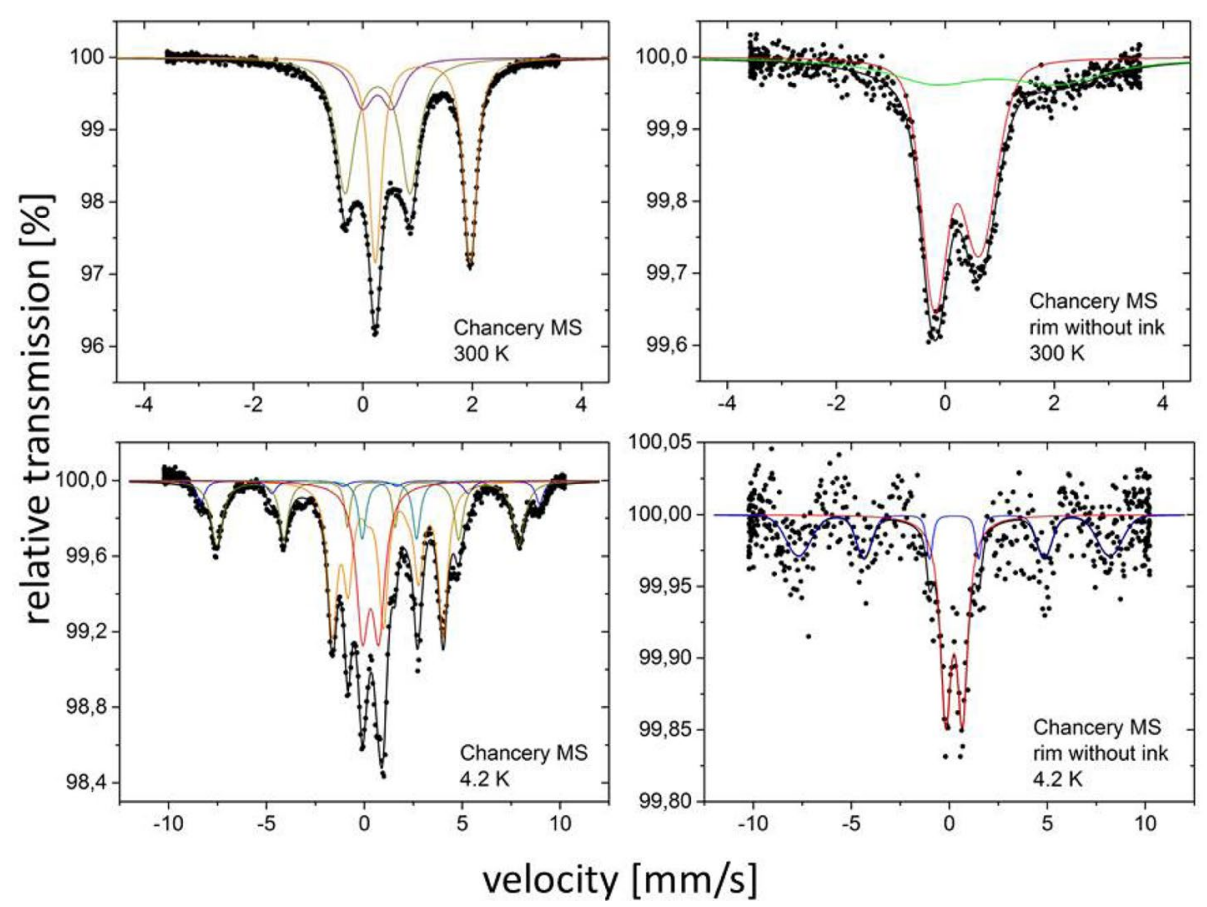

Fig. 3 Room temperature (top) and $4.2 \mathrm{~K}$ (bottom) Mössbauer spectra of the Chancery MS (left) and its rim without ink (right). In all four spectra data points are shown as black dots; the black lines are the fits of the overall spectra. The individual spectral components of the part with writing (left) are given as colored lines: the pink and the olive lines are due to $\mathrm{Fe}^{3+}$ quadrupole doublets of which the latter one with the larger quadrupole splitting can be assigned to hydronium jarosite; the orange line is due to a Fe ${ }^{2+}$ quadrupole doublet assigned to Fe(II)-oxalate. In the low temperature spectrum the olive and the orange Fe doublets further split into the typical magnetic sextet of the jarosite and the octet of the Fe(II)-oxalate, respectively. The second $\mathrm{Fe}^{3+}$ doublet remains unchanged (pink line). Two new features of minor contribution appear, the first is a magnetic hyperfine pattern (blue line) due to a $\mathrm{Fe}^{3+}$ site with slow paramagnetic relaxation and the dark cyan line can assigned to a $\mathrm{Fe}^{2+}$ quadrupole doublet. The room temperature Mössbauer spectrum of the rim show two components: a Fe ${ }^{3+}$ doublet (red) and a Fe ${ }^{2+}$ doublet (green) with an unusually small quadrupole splitting; the corresponding $4.2 \mathrm{~K}$ spectrum shows again the $\mathrm{Fe}^{3+}$ doublet (red) and a sextet due to magnetic hyperfine splitting (blue) 


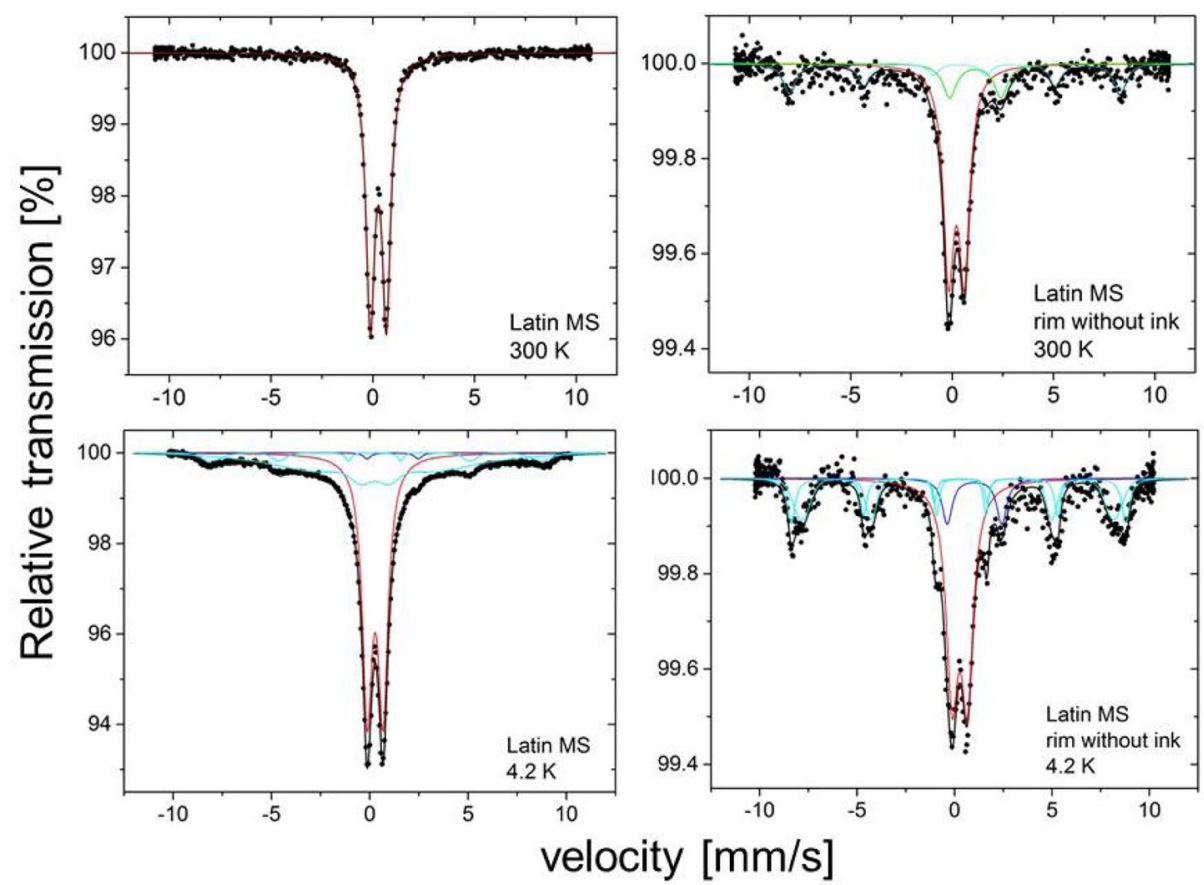

Fig. 4 Room temperature (top) and 4.2 K (bottom) Mössbauer spectra of the cut out calligraphic letters of the Latin MS (left) and the paper without letters (right). In the spectra of both samples the data points are shown as black dots; the black lines are the fits of the overall spectra. The individual spectral components are given as colored lines: the red lines are due to $\mathrm{Fe}^{3+}$ quadrupole doublets; the violet line in the $4.2 \mathrm{~K}$ spectrum of the calligraphic letters and the dark cyan lines in both spectra of the rim are due to $\mathrm{Fe}^{2+}$ quadrupole doublets with different quadrupole splitting values. The bright blue lines in the low temperature spectrum of the calligraphic letters originate from $\mathrm{Fe}^{3+}$ sites exhibiting slow paramagnetic relaxations. In the room temperature as well as in the $4.2 \mathrm{~K}$ spectrum of the rim there is a well-pronounced Fe ${ }^{3+}$ sextet originating from magnetic hyperfine splitting

the absorbers and the total area under the Mössbauer spectra at $4.2 \mathrm{~K}$ and room temperature calculated by the fitting procedure as the product of the fractional depth and the width of the individual lines in the spectra and summed over all lines. Table 2 gives the hyperfine parameters obtained for the individual components obtained from the least squares fits of the Mössbauer spectra.

From the spectral areas given in Table 1 one can estimate the area density of iron in the absorbers, and hence the iron content per unit mass of the absorber material. For this, separate reference measurements with a hematite absorber of known thickness were taken under similar conditions as for the measurements of the documents. The intensity of a component in a Mössbauer spectrum is proportional to the product of its abundance and its recoil-free fraction, or Lamb-Mössbauer factor $f$ [27]. Assuming that the f-factors of all components in the spectra of the documents are the same as that of hematite, one can then obtain the iron contents of the document samples. The iron contents obtained in this way are given in Table 1 , as are the measured $\mathrm{pH}$ values of the papers. The main uncertainty in the determination of the iron contents of the document samples results from the assumption of equal $\mathrm{f}$-factors for the hematite reference and the iron species on the papers. Since hematite has one of the largest f-factors known for iron compounds and other iron oxides and oxy-hydroxides have similarly high f-factors of about 0.9 at $4.2 \mathrm{~K}$ and 0.85 at room temperature $[44,45]$, the relative uncertainty in the results for the iron contents should be no more than about 5 per cent if all iron were present in the documents as oxides or oxy-hydroxides. Iron compounds with organic ligands, however, may have substantially lower f-factors, which are also expected to decrease more strongly with increasing temperature. As an example, and because iron oxalate is the only iron phase with organic ligands that could be unambiguously identified in one of the documents, we have measured the f-factors of $\mathrm{Fe}(\mathrm{II})$-oxalate at $4.2 \mathrm{~K}$ and at room temperature as described in the Experiments and methods section. The result, $\mathrm{f}(4.2 \mathrm{~K})=0.75(2)$ and $\mathrm{f}(300 \mathrm{~K})=0.34(2)$ shows that expectedly $\mathrm{f}$ decreases substantially between $4.2 \mathrm{~K}$ and room temperature. The iron content of the samples from the documents as given in Table 1 for measurements at $4.2 \mathrm{~K}$ may thus be underestimated by about $20 \%$ if the iron is bound to organic ligands. The iron contents obtained from the room 


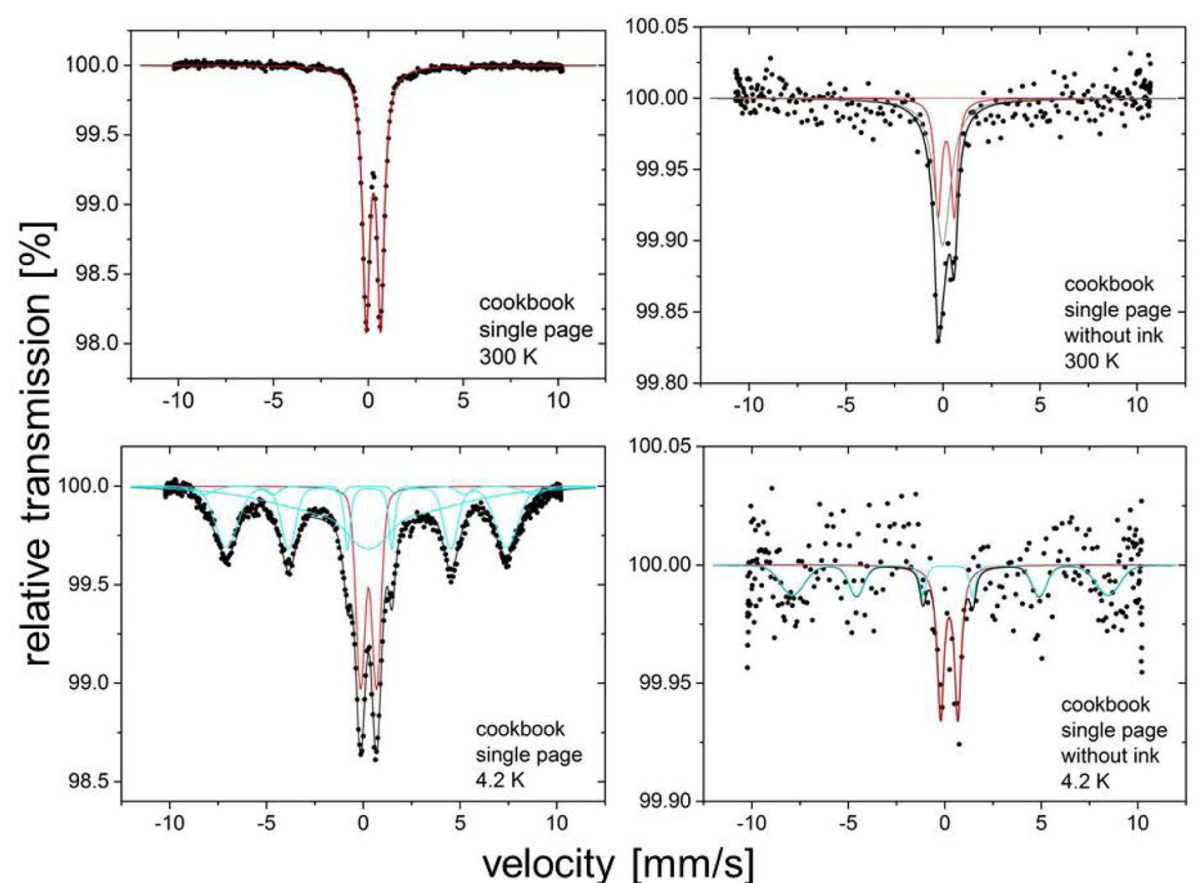

Fig. 5 Room temperature (top) and $4.2 \mathrm{~K}$ (bottom) Mössbauer spectra of a written (left) and an empty page (right) of the cooking book. In all the spectra the data points are shown as black dots and the black lines are the fits of the overall spectra. The individual spectral components are given as colored lines. In all four spectra there is a $\mathrm{Fe}^{3+}$ quadrupole doublet (red lines) with roughly the same quadrupole splitting. In the low temperature spectra of the written as well as in the empty page there are magnetic sextets (dark blue): two in the written page and one in the empty page. In the $4.2 \mathrm{~K}$ spectrum of the written page there is a very broad feature (bright blue) due to $\mathrm{Fe}^{3+}$ showing slow paramagnetic relaxation

temperature spectra may be underestimated much more, which explains the lower iron contents obtained from the room temperature spectra. Lower values for the iron contents obtained for the papers with writing at room temperature compared to $4.2 \mathrm{~K}$ (Table 1 ) therefore do not mean, that the iron contents are really lower, but merely that there is a substantial decrease of the f-factors of the iron species with increasing temperature. Assuming that a similar decrease of the f-factor as was found for ferrous oxalate occurs for all iron species bound to organic ligands, one can conclude that most of the iron in the inked papers forms bonds with organic ligands.

For the iron in the ink-free papers, roughly the same iron contents are obtained from the room temperature and $4.2 \mathrm{~K}$ measurements. This indicates that the iron in the papers is present largely as oxidic phases whose f-factors change with temperature much like that of hematite or goethite. For the paper of the cookbook, the determination of the iron content from the $4.2 \mathrm{~K}$ spectra is subject to a considerable uncertainty because, due to the low iron content, the intensity of the magnetically split pattern at $4.2 \mathrm{~K}$ is subject to a large statistical uncertainty. Even with an estimated uncertainty of the iron content obtained from Mössbauer spectroscopy at $4.2 \mathrm{~K}$ similar to that of $20 \%$ for the inked papers, it is clear that all ink-free papers contain about a factor of ten less iron than the parts with writing.

With $21 \mathrm{mg} / \mathrm{g}$, the parts with writing of the Latin MS contain more iron than the Chancery $M S(6 \mathrm{mg} / \mathrm{g})$, probably because the large letters in the Latin $M S$ could be cut out with very little ink-free paper adhering, which was not the case for the Chancery MS. The cookbook contains much less iron than the Chancery MS, perhaps because the ink contained less iron. The papers of the manuscripts studied in this work always contain about a factor of ten less iron than the papers with applied ink. One can therefore largely neglect the iron in the paper when one interprets the iron species found in inked parts. In the interpretation of weak components in the spectra of inked papers one should, however, keep the presence of iron in the paper in mind.

The absolute iron contents of the papers are between 0.2 and $1 \mathrm{mg}$ of Fe per gram of paper (Table 1). Such iron contents are common in old papers [46-48]. The iron is found to be mainly trivalent, with at best minor traces of ferrous iron in the papers of the Chancery MS and the Latin MS. In a recent Mössbauer study of some papers without ink Dzinavatonga et al. [26] came to a similar conclusion, but they do not give absolute values for the iron contents of their papers. The presence 
Table 2 Mössbauer parameters obtained at room temperature and $4.2 \mathrm{~K}$ for the studied historical documents

\begin{tabular}{|c|c|c|c|c|c|c|c|c|c|c|}
\hline \multirow[t]{2}{*}{ Material and assignment } & \multicolumn{5}{|c|}{ Room temperature spectrum } & \multicolumn{5}{|c|}{$4.2 \mathrm{~K}$ spectrum } \\
\hline & IS [mm/s] & $\mathrm{QS}[\mathrm{mm} / \mathrm{s}]$ & $\mathrm{B}[\mathrm{T}]$ & $\mathrm{W}[\mathrm{mm} / \mathrm{s}]$ & $\mathrm{A}[\%]$ & IS [mm/s] & $\mathrm{QS}[\mathrm{mm} / \mathrm{s}]$ & $\mathrm{B}[\mathrm{T}]$ & $\mathrm{W}[\mathrm{mm} / \mathrm{s}]$ & $\mathrm{A}[\%]$ \\
\hline \multicolumn{11}{|l|}{ Chancery MS part with writing } \\
\hline Iron oxalate & $1.09(1)$ & $1.73(1)$ & - & $0.28(1)$ & $42(2)$ & $1.08(1)$ & $-1.96(4)$ & $15.3(1)$ & $0.57(1)$ & $42(1)$ \\
\hline Hydronium jarosite & $0.27(1)$ & $1.24(1)$ & - & $0.26(1)$ & $17(2)$ & $0.26(1)$ & $-0.18(1)$ & $47.8(2)$ & $0.82(2)$ & $22(1)$ \\
\hline Ferric iron doublet & $0.27(1)$ & $0.84(2)$ & - & $0.67(2)$ & $41(2)$ & $0.33(2)$ & $0.79(2)$ & - & $0.97(7)$ & 23(1) \\
\hline Ferric iron sextet & & & & & & $0.28(2)$ & $0.05(3)$ & $53.8(2)$ & $0.58(4)$ & $5(1)$ \\
\hline Ferrous iron doublet & & & & & & 1.15 & $2.75(3)$ & - & $0.69(4)$ & $8(1)$ \\
\hline \multicolumn{11}{|c|}{ Chancery MS paper without ink } \\
\hline Ferric iron doublet 1 & $0.14(2)$ & $0.55(4)$ & - & $0.51(6)$ & $51(7)$ & $0.25(2)$ & $0.82(3)$ & - & $0,57(4)$ & $50(3)$ \\
\hline Ferric iron doublet 2 & $0.24(2)$ & $1.08(3)$ & - & $0.38(4)$ & $35(7)$ & & & & & \\
\hline Ferric iron goethite & & & & & & 0.26 & $-0.22(8)$ & 49.1 & $0.25^{*}$ & $41(3)$ \\
\hline Ferrous iron doublet & 1.0 & $1.87(12)$ & - & 0.75 & $14(3)$ & $0.94(13)$ & 3.6(3) & - & 0.75 & $9(2)$ \\
\hline \multicolumn{11}{|c|}{ Latin MS letters with little paper } \\
\hline Ferric iron & $0.28(1)$ & $0.79(1)$ & - & $0.51(1)$ & 100 & $0.28(1)$ & $0.81(1)$ & - & $0.61(1)$ & $59(1)$ \\
\hline Ferric iron & & & & & & $0.29(1)$ & $0.10(1)$ & $52.1(5)$ & $0.25^{*}$ & $6(1)$ \\
\hline Ferric iron & & & & & & 0.26 & 0.0 & 26(1) & $0.25^{*}$ & $34(3)$ \\
\hline Ferrous iron & & & & & & 1.16 & 2.60 & - & $0.25^{*}$ & $1.1(5)$ \\
\hline \multicolumn{11}{|l|}{ Latin MS paper without ink } \\
\hline Ferric iron doublet & $0.22(2)$ & $0.77(3)$ & - & $0.64(3)$ & $66(2)$ & $0.27(1)$ & $0.77(1)$ & - & $0.72(2)$ & $52(2)$ \\
\hline Hematite & $0.25(2)$ & $-0.25(4)$ & $50.6(2)$ & $0.54(8)$ & $20(2)$ & 0.26 & $-0.11(3)$ & $53.3(2)$ & $0.47(8)$ & $15(5)$ \\
\hline Ferric iron(goethite) & & & & & & $0.26(1)$ & $-0.18(3)$ & $49.7(5)$ & $0.25^{*}$ & $23(5)$ \\
\hline Ferrous iron & $1.14(9)$ & $2.52(20)$ & - & $0.77(12)$ & $14(2)$ & $0.98(3)$ & $2.85(6)$ & - & 0.50 & $10(2)$ \\
\hline \multicolumn{11}{|l|}{ Cookbook pages 50-70 } \\
\hline Ferric iron & $0.26(1)$ & $0.75(1)$ & - & $0.49(1)$ & 100 & \multicolumn{5}{|c|}{ Not measured } \\
\hline \multicolumn{11}{|l|}{ Cookbook single page cut } \\
\hline Ferric iron & $0.27(1)$ & $0.77(1)$ & - & $0.45(1)$ & 100 & $0.28(1)$ & $0.80(1)$ & - & $0.56(1)$ & $34(1)$ \\
\hline Ferric iron (lepidocrocite) & & & & & & $0.25(1)$ & $-0.16(1)$ & $45.0(1)$ & 0.25 & 29(1) \\
\hline Ferric iron & & & & & & 0.26 & 0 & 52 & $0.25^{*}$ & $4(1)$ \\
\hline Ferric iron & & & & & & 0.26 & 0 & $32(1)$ & $0.25^{*}$ & $32(2)$ \\
\hline Ferrous iron & & & & & & $1.01(3)$ & $2.87(6)$ & - & & $1(1)$ \\
\hline \multicolumn{11}{|l|}{ Cookbook paper only } \\
\hline Ferric iron & $0.12(3)$ & $0.70(3)$ & - & $0.63(4)$ & 100 & $0.22(3)$ & $0.88(5)$ & & $0.42(7)$ & $52(6)$ \\
\hline Ferric iron & & & & & & 0.26 & $0.21(1)$ & $51.0(6)$ & $0.25^{*}$ & $48(6)$ \\
\hline \multicolumn{11}{|l|}{ Iron oxalate } \\
\hline Ferrous iron & $1.09(1)$ & $1.74(1)$ & - & $0.25(1)$ & 100 & $1.09(1)$ & $-1.94(1)$ & $14.9(1)$ & $0.27(1)$ & 100 \\
\hline \multicolumn{11}{|l|}{ Hydronium Jarosite } \\
\hline Ferric iron & $0.27(1)$ & $1.25(1)$ & - & $0.29(1)$ & $89(1)$ & $0.24(1)$ & $-0.13(1)$ & $48.5(2)$ & $0.38(2)$ & $78(1)$ \\
\hline Ferrous iron & $1.17(3)$ & $2.27(3)$ & - & $0.55(5)$ & $11(1)$ & $1.14(1)$ & $3.14(2)$ & - & 0.25 & $22(1)$ \\
\hline
\end{tabular}

IS is the isomer shift relative to the $57 \mathrm{Co}:$ Rh source having the same temperature as the absorber. $\mathrm{QS}=\mathrm{eQVzz} / 2 \cdot(1+\eta 2 / 3) 1 / 2$ is the electric quadrupole interaction, $B$ is the magnetic hyperfine field at the iron nuclei, $W$ is the full width at half maximum of the Mössbauer lines and $A$ is the relative area of the individual components in the Mössbauer spectrum. Values in parentheses are the last digit errors. When no error is given, the value was fixed during the fit. Components that cannot be identified with specific iron compounds are designated merely as ferric or ferrous iron. In some cases, magnetically split components were fitted with a Gaussian distribution of hyperfine fields. This is indicated by an asterisk behind the value of the Lorentzian line-width used for the distribution. More details of this are given in the text

of iron in old papers may arise from contamination of the water used in paper production, from wear of the machinery used in making the paper pulp from rags, from the use of additives, or from iron oxides or hydroxides like hematite or goethite adhering to the rags used for making the paper [49]. 


\section{Mössbauer spectra of the papers without ink}

The room temperature (Figs. 3, 4 and 5, top right) as well as the $4.2 \mathrm{~K}$ spectra (Fig. 3 - 5, bottom right) of all papers are dominated by a ferric quadrupole doublet with a splitting of about $0.8 \mathrm{~mm} / \mathrm{s}$. In the low temperature spectra of all three papers (Figs. 3, 4 and 5, bottom right) at least one sextet due to magnetic hyperfine splitting appears. The paper of the Latin MS exhibits a weak magnetic sextet already at room temperature. According to its hyperfine parameters (Table 2) this can be attributed to hematite. At $4.2 \mathrm{~K}$, the hematite is still visible with a hyperfine field of $53.3 \mathrm{~T}$. It does not undergo the Morin transition, which shows that it is present as rather small or badly crystallized particles. An additional magnetic component with rather broad lines in the $4.2 \mathrm{~K}$ spectrum of the paper of the Latin $M S$ was fitted with a Gaussian distribution of hyperfine fields $(B=49.7 \mathrm{~T}$ and $\sigma_{\mathrm{B}}=2.4 \mathrm{~T}$ ). These hyperfine parameters suggest that this component may represent small goethite particles that exhibit only a quadrupole doublet at room temperature because of superparamagnetism, but split magnetically at $4.2 \mathrm{~K}[50,51]$. The $4.2 \mathrm{~K}$ spectrum of the paper of the cookbook also seems to contain a magnetically split pattern, but the poor statistical accuracy of the spectrum makes it impossible to interpret this in terms of a specific iron compound. In the room temperature spectrum of the paper of the Chancery $M S$ (Fig. 3, top right) a weak ill-defined ferrous doublet seems to be present, which is hardly visible at $4.2 \mathrm{~K}$. In the paper of the Latin $M S$, a minor amount of ferrous iron is definitely present. In the paper of the cookbook, no ferrous iron can be seen.

\section{Mössbauer spectra of the papers with applied ink}

Table 2 gives the hyperfine parameters for the individual components obtained from the least squares fits of the Mössbauer spectra. The room temperature spectrum of the Chancery MS (Fig. 3, top left) is dominated a ferrous quadrupole doublet with $\mathrm{QS}=1.73 \mathrm{~mm} / \mathrm{s}$, IS $=1.09 \mathrm{~mm} / \mathrm{s}$ and $42 \%$ of the spectral area. The ferric component making up the rest of the spectrum required two quadrupole components for a satisfactory fit, namely a doublet with rather narrow lines, $17 \%$ of the area and an uncommonly large QS value of $1.23 \mathrm{~mm} / \mathrm{s}$. and a broad doublet making up the remainder of the spectrum. This broad doublet probably represents several different species, whose individual contributions cannot be resolved.

In the rather complicated $4.2 \mathrm{~K}$ spectrum (Fig. 3, bottom left) the dominant $\mathrm{Fe}^{2+}$ component exhibits a magnetic hyperfine splitting into an octet pattern, as is expected for ferrous iron in magnetically ordered substances [52]. This octet could be fitted with a hyperfine field of $\mathrm{B}=15.3 \mathrm{~T}$, a quadrupole interaction of $\mathrm{QS}=-$ $1.96 \mathrm{~mm} / \mathrm{s}$, and an asymmetry parameter of the electric field gradient of $\eta=0.68$. One should note that the octet pattern allows the sign of the electric quadrupole interaction to be determined, while from the doublet observed at room temperature only the magnitude of QS can be obtained. For the angles defining the direction of the hyperfine field in the coordinate system of the electric field gradient [52], values of $\theta=90^{\circ}$ and $\phi=0^{\circ}$ were assumed and fixed during the least squares fit. This $\mathrm{Fe}^{2+}$ component is very similar to one observed in a degraded document by Danon et al. [24],who assigned it to hydrated $\mathrm{Fe}(\mathrm{II})$-oxalate, $\mathrm{FeC}_{2} \mathrm{O}_{4} \cdot 2 \mathrm{H}_{2} \mathrm{O}$. Room temperature and $4.2 \mathrm{~K}$ spectra taken of a commercially obtained Fe(II)-oxalate (Fig. 6, top, and Table 2) are in good agreement with the $\mathrm{Fe}^{2+}$ sites in the Chancery $M S$ and with published spectra of iron oxalate [53, 54]. In fact, the Mössbauer patterns of $\mathrm{Fe}(\mathrm{II})$-oxalate at room temperature and $4.2 \mathrm{~K}$ are very typical and it is therefore possible to identify this compound unambiguously by Mössbauer spectroscopy. Even the quadrupole doublet of ferrous oxalate observed at room temperature alone is quite typical for this compound and allows its identification in inked papers with high reliability.

The narrow quadrupole doublet of the $\mathrm{Fe}^{3+}$ component with $\mathrm{QS}=1.23 \mathrm{~mm} / \mathrm{s}$ in the room temperature spectrum of the Chancery $M S$ splits at $4.2 \mathrm{~K}$ into a magnetic sextet that can be fitted with a magnetic hyperfine field of $\mathrm{B}=47.8 \mathrm{~T}$, a quadrupole shift of $\mathrm{QS}=-0.12 \mathrm{~mm} / \mathrm{s}$ and an isomer shift of IS $=0.26 \mathrm{~mm} / \mathrm{s}$ (Table 2). These parameters are in good agreement with published data for hydronium jarosite $\left(\mathrm{H}_{3} \mathrm{O}\right) \mathrm{Fe}_{3}\left(\mathrm{SO}_{4}\right)_{2}(\mathrm{OH})_{6}[55,56]$ and with the fitting data of the Mössbauer spectrum of the sample of hydronium jarosite which was obtained by allowing an aqueous solution of $\mathrm{Fe}$ (II)-sulfate to evaporate to dryness at room temperature within a few weeks (Fig. 6, bottom. and Table 2). The spectra of the dried solution of ferrous sulfate still contain a weak ferrous quadrupole doublet that cannot unambiguously be assigned to any of the hydrous ferrous sulfates for which Mössbauer parameters have been measured [57-59]. The large ferric quadrupole splitting of jarosite at room temperature and the Mössbauer parameters at $4.2 \mathrm{~K}$ are a very typical signature of jarosite, whose presence therefore can be considered as established. It is, however, not utterly clear whether the jarosite in the Chancery MS is hydronium jarosite or potassium jarosite, since the latter might have formed with potassium present in the paper $[47,48]$. A distinction of jarosites, $\mathrm{MFe}_{3}\left(\mathrm{SO}_{4}\right)_{2}(\mathrm{OH})_{6}$, with different $\mathrm{M}$ anions on the basis of the Mössbauer spectra is difficult, because the hyperfine parameters are very similar [56].

Surprisingly, the relative intensities of the quadrupole doublets obtained for the Chancery MS at room temperature for $\mathrm{Fe}(\mathrm{II})$-oxalate and jarosite (42 and 

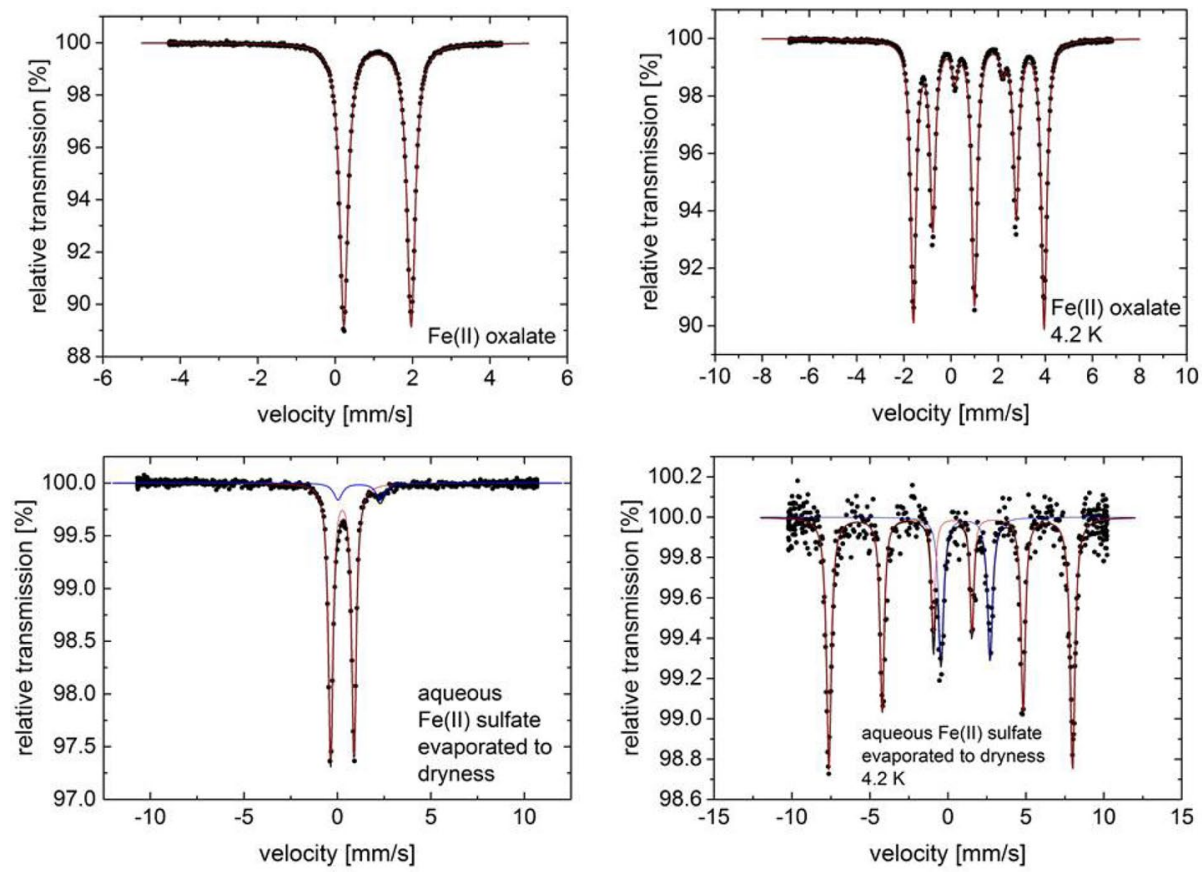

Fig. 6 Room temperature (left) and 4.2 K (right) Mössbauer spectra of Fe(II)-oxalate (top) and hydronium jarosite (bottom)

$17 \%$, respectively, Table 2) are nearly the same as those obtained for the magnetically split spectra at $4.2 \mathrm{~K}$ (42 an $23 \%$, Table 2). This suggests that the f-factor of jarosite decreases with increasing temperature in similar way as that of $\mathrm{Fe}(\mathrm{II})$-oxalate. To verify this, we have measured the $\mathrm{f}$-factor for potassium jarosite in the same manner as that of $\mathrm{Fe}(\mathrm{II})$-oxalate and obtained $\mathrm{f}(4.2 \mathrm{~K})=0.74$ and $\mathrm{f}(300 \mathrm{~K})=0.44$, i.e., nearly as strong a decrease with increasing temperature as for the oxalate. This can explain that the relative intensities of the two components in the spectra taken at $4.2 \mathrm{~K}$ and at ambient temperature are nearly the same.

In the room temperature spectrum of the Chancery $M S$ a second broad $\mathrm{Fe}^{3+}$ doublet with a quadrupole splitting of QS $=0.84 \mathrm{~mm} / \mathrm{s}$ and a fractional area of $41 \%$ is needed to obtain a good fit. At $4.2 \mathrm{~K}$ a rather strong ferric doublet (23\%) with $\mathrm{QS}=0.83 \mathrm{~mm} / \mathrm{s}$ is still present, and an additional weak (7\%) magnetic sextet with a hyperfine field of $53.7 \mathrm{~T}$ and a very small electric quadrupole interaction is observed. Thus, part of the iron species that give rise to the broad ferric doublet in the room temperature spectrum split magnetically at $4.2 \mathrm{~K}$, while the rest remains a quadrupole doublet. This indicates that there may be two different iron species, of which only one shows a magnetic splitting at $4.2 \mathrm{~K}$. The fit also requires an additional minor (8\%) $\mathrm{Fe}^{2+}$ doublet that is difficult to see in the spectrum, but is needed to get the intensities of the lines right. When the isomer shift is arbitrarily restrained to $1.15 \mathrm{~mm} / \mathrm{s}$, a value typical for ferrous iron with six $\mathrm{H}_{2} \mathrm{O}$ ligands, a quadrupole splitting of $\mathrm{QS}=2.75 \mathrm{~mm} / \mathrm{s}$ is obtained. We cannot assign this doublet to a specific iron species. In the room temperature spectrum no corresponding doublet is visible, perhaps because at $300 \mathrm{~K}$ the f-factor of this ferrous species is too low.

The room temperature Mössbauer spectrum of the Latin MS (Fig. 4, top left) exhibits only one $\mathrm{Fe}^{3+}$ doublet with $\mathrm{QS}=0.79 \mathrm{~mm} / \mathrm{s}$. At $4.2 \mathrm{~K}$ there is still a ferric quadrupole doublet with practically the same QS making up 59\% of the spectral area. The remainder splits magnetically into a broad unresolved pattern with $34 \%$ of the spectral area and an additional magnetic sextet with a hyperfine field of $52.1 \mathrm{~T}$ and $6 \%$ of the area. In the fit, these patterns were approximated by two static Gaussian distributions of hyperfine fields, one with a very broad distribution of hyperfine fields around a mean value of $26 \mathrm{~T}$ with a variance of $\sigma_{\mathrm{B}}=20 \mathrm{~T}$, and the other with a much narrower distribution around a mean field of $52.1 \mathrm{~T}$ with a variance of $\sigma_{\mathrm{B}}=3.2 \mathrm{~T}$. In reality, both magnetic patterns seem to result from slow paramagnetic relaxations of the spins of ferric ions rather than static distributions of hyperfine fields, as will be discussed later. In the $4.2 \mathrm{~K}$ spectrum there is also a very weak ferrous doublet with only about $1 \%$ of the spectral area, which gives rise to a small bulge in the spectrum at about $+2.5 \mathrm{~mm} / \mathrm{s}$. The location of the second component of this doublet cannot 
be seen below the strong ferric doublet. The parameters of this component therefore had to be fixed to plausible values in the fit and must be considered as rough approximations. Therefore it does not make sense to speculate what this component might be.

The room temperature Mössbauer spectrum of the cookbook (Fig. 5, top left) exhibits only a ferric quadrupole doublet with a quadrupole splitting of $0.77 \mathrm{~mm} / \mathrm{s}$. The $4.2 \mathrm{~K}$ spectrum (Fig. 5, bottom left) is still dominated by a ferric quadrupole doublet with $24 \%$ of the area, but the remainder of the iron exhibits magnetic hyperfine interactions. One can distinguish three patterns, which were all fitted with Gaussian distributions of hyperfine fields. Of these, the rather clearly defined sextet with $\mathrm{B}=44.9 \mathrm{~T} \sigma_{\mathrm{B}}=2.8 \mathrm{~T}$ and $29 \%$ of the spectral area can tentatively be assigned to lepidocrocite $(\gamma-\mathrm{FeOOH})[60$, 61], perhaps as small particles causing the line broadening. Lepidocrocite is paramagnetic at room temperature and orders magnetically below about $70 \mathrm{~K}[60,61]$. The other two components are similar to those found in the Latin $M S$ at $4.2 \mathrm{~K}$ and can be explained in the same way as arising from to slow paramagnetic relaxations.

A common feature found in all studied samples are quadrupole doublets of $\mathrm{Fe}^{3+}$ species with isomer shifts of about $0.3 \mathrm{~mm} / \mathrm{s}$ and quadrupole splittings of about $0.8 \mathrm{~mm} / \mathrm{s}$ at room temperature. Part of this ferric iron splits magnetically at $4.2 \mathrm{~K}$, probably because of slow and intermediate paramagnetic relaxations [62], which occur typically for isolated ferric ions, i.e. for ions that are so far apart that the magnetic dipole interaction between their magnetic moments becomes too weak to cause spin-spin relaxation processes. These are processes in which the spins of two neighbouring atoms change direction at the same time. The spatial separation may be caused by large organic ligands or any other cause of dilution of the ferric ions. At low temperatures, when spin-lattice relaxation also becomes slow, one then often observes magnetic hyperfine splittings because the hyperfine fields at the ${ }^{57} \mathrm{Fe}$ nuclei change direction so rarely that they appear static to the nuclear magnetic moment. For $\mathrm{Fe}^{3+}$ ions, the spectra then often resemble those of magnetically ordered substances, with hyperfine fields well above $50 \mathrm{~T}$. When the relaxation is not sufficiently slow, broadened magnetic patterns may occur. For the iron in the inked papers, the observation of slow relaxation Mössbauer patterns means that the ferric ions are separated from each other sufficiently to suppress magnetic interactions. It is improbable that these magnetic hyperfine patterns are due to small magnetically ordered oxidic clusters similar to ferrihydrite, because these exhibit typical magnetic sextet patterns with broad lines and mean hyperfine fields around $50 \mathrm{~T}$ or below at $4.2 \mathrm{~K}$ [28].
An even partial assignment of the $\mathrm{Fe}^{3+}$ species to crystalline Fe(III)-gallate described by Wunderlich [39] can be ruled out because this compound shows completely different Mössbauer parameters, particularly when it is magnetically ordered at $4.2 \mathrm{~K}[29,30]$. On the basis of the quadrupole splitting at room temperature and the magnetic hyperfine pattern at $4.2 \mathrm{~K}$, one can also rule out an assignment to the second modification of $\mathrm{Fe}(\mathrm{III})$ gallate, which probably exists only as nanoparticles or may even be amorphous [31], the Fe(III) gallate(2) of $[29,30]$. This iron gallate exhibits a broad quadrupole doublet at room temperature, but with a splitting that is substantially larger (QS $\approx 1.1 \mathrm{~mm} / \mathrm{s}$ ) $[29,31]$ than the doublets observed in the manuscripts at room temperature. It also exhibits a rather typical magnetic hyperfine splitting at $4.2 \mathrm{~K}$ [29] and is definitely not present in the studied manuscripts in amounts detectable in the Mössbauer spectra. A reason for this may be the instability of the gallate thought to be responsible for the black coloration of the ink [31].

For a tentative assignment of the $\mathrm{Fe}^{3+}$ site with a quadrupole splitting of about $0.8 \mathrm{~mm} / \mathrm{s}$ it is worth noting that papers impregnated with various ink preparations usually show such iron species [30] and that even a paper impregnated with a freshly prepared Fe(II)-sulfate solution without polyphenols after drying showed mainly a $\mathrm{Fe}^{3+}$ site with a $\mathrm{QS}=0.74 \mathrm{~mm} / \mathrm{s}$ [30]. Iron gallate or other polyphenol complexes are certainly present in the ink when it is written on paper, but the majority of the constituents of the ink still seem to be unreacted [30]. On the paper, the still unreacted polyphenols of the ink may react with the iron of the ferrous sulfate to form more polyphenols, but the exact nature of these is still unclear. Mössbauer studies of ink precipitates [30,32] show that there are indeed components in the Mössbauer spectra with quadrupole interactions around $0.8 \mathrm{~mm} / \mathrm{s}$. It is, however, also possible that the ferrous sulfate dissolved in the ink penetrates into the paper and there reacts with the cellulose. That such reactions take place is shown by the Mössbauer spectrum of a paper impregnated with a solution of ferrous sulfate only [30]. The exact nature of these species cannot be determined from the Mössbauer data. The iron may react with and be attached to the cellulose fibers or to disintegration products of these, or, less probably, react with the gum arabic used as a binder in the ink. The reaction of the ferrous iron of the sulfate on the paper must go along with an oxidation, since in freshly impregnated dried papers, part of the iron is still $\mathrm{Fe}^{2+}[30]$. Of this we see at best very little in the Latin MS and the cookbook, probably because the initially ferrous species oxidize in the course of time. It is also worth noting that the QS values of all our samples 
$(0.75-0.85 \mathrm{~mm} / \mathrm{s})$ are close to the QS values of ironsaccharose or iron-maltose complexes [62,63], as well as iron-humic acid or iron-polysaccharide composites $[64,65]$. In contrast to the iron in the historic Manuscripts, however, these composites usually show the typical magnetic hyperfine splitting of ferrihydrite [64, $65]$ at $4.2 \mathrm{~K}$.

In the Chancery MS one also observes the presence of jarosite. While the Mössbauer signature of jarosite is unambiguous, it is not clear whether the Chancery MS contains hydronium or potassium jarosite, since the Mössbauer parameters of these are too similar to allow a distinction. Potassium could be present in the paper $[47,48]$ or, less probably, in the ink. The formation of jarosite may be due to an excess of ferrous sulfate. It has been shown to occur in solid samples of unbalanced and aged model inks [32]. A low pH value of the inked paper should be favorable to the occurrence of jarosite, which forms only in the $\mathrm{pH}$ range up to 4 [66]. The $\mathrm{pH}$ of about 4 of the Chancery MS is in agreement with this notion. Jarosite seems to form only rarely in old Manuscripts, since it has not been discovered before by Mössbauer spectroscopy and the conditions under which it forms still need to be clarified.

The presence of $\mathrm{Fe}(\mathrm{II})$-oxalate in the Mössbauer spectra of the Chancery MS may appear surprising, but the formation of ferrous oxalate does not seem to be rare. Apart from the three documents studied in this work, there were two ancient documents studied by Danon et al. $[24,25]$, and three more from the National Library of Poland studied by Wagner et al. [20], who did not make measurements at $4.2 \mathrm{~K}$. In the room temperature spectra of one of their three studied documents, Wagner et al. observe a prominent quadrupole doublet with the isomer shift and quadrupole splitting of ferrous oxalate, though they do not explicitly mention the presence of this compound. Thus, four out of the eight historical documents studied so far by Mössbauer spectroscopy contain ferrous oxalate.

The formation of the Fe-oxalate must be related with aging or degradation processes because it does not appear within days after ink was freshly written on paper [30]. Oxalic acid is one of the degradation products of cellulose under conditions of natural aging $[3,67]$. Together with the presence of ferrous iron, the formation of the insoluble $\mathrm{Fe}(\mathrm{II})$-oxalate is quite probable. The formation of ferrous oxalate during the artificial ageing of paper impregnated with model inks has been observed by Arčon et al. [22], who studied papers impregnated with model iron gall inks by XANES and Mössbauer spectroscopy at RT. A paper aged at $80{ }^{\circ} \mathrm{C}$ and $65 \%$ relative humidity for 7 days at a rather low $\mathrm{pH}$ value shows the typical quadrupole doublet of ferrous oxalate in its room temperature Mössbauer spectrum. The formation of $\mathrm{Fe}(\mathrm{II})$-oxalate was also observed by infrared spectroscopy in papers soaked with solutions of $\mathrm{FeCl}_{3}$ after two decades of ageing at ambient temperature [68], but chemical details of its formation still appear to need clarification.

It is also possible that polyphenol complexes of the inks decompose to $\mathrm{Fe}(\mathrm{II})$-oxalate with iron from the iron sulfate. For example, a ferrous component found as a by-product in the synthesis of the amorphous or microcrystalline modification $\mathrm{Fe}(\mathrm{III})$-gallate from ferrous sulfate and gallic acid at about $100{ }^{\circ} \mathrm{C}$ [29] is clearly ferrous oxalate, although the authors did not recognize it as such. The exact conditions, under which ferrous oxalate forms in old documents still need clarification but prolonged storage in a warm and moist environment may be favorable for its formation. One can also not rule out that the binder in the ink of old documents, mostly gum arabic, decomposes to oxalic acid and forms oxalate with the iron of the ink.

There is no Fe(II)-oxalate in the Latin MS and in the cookbook according to the Mössbauer spectra. This could be an indication for less severe paper modification, perhaps due to the low acidity of these two documents indicated by $\mathrm{pH}$ values of 4.7 and even higher compared to about 4.0 for the Chancery MS (Table 1). Ferrer and Sistach [69, 70], however, found Fe(II)-oxalate in documents showing $\mathrm{pH}$ values of 4.7, 5.5-5.8 and even above 6 . It therefore appears unclear, whether there is any correlation between the $\mathrm{pH}$ and the existence of $\mathrm{Fe}(\mathrm{II})$-oxalate in ancient Manuscripts.

\section{Conclusions}

In the three Manuscripts studied in this work, the presence of both the crystalline $[29,39,40]$ and the nanocrystalline or amorphous modification of iron gallate [29,31] can be ruled out, because their typical magnetic hyperfine interactions in the $4.2 \mathrm{~K}$ Mössbauer spectra were not observed. The nature of the component in the Mössbauer spectra that is a ferric quadrupole doublet at room temperature and partially splits magnetically at $4.2 \mathrm{~K}$ is difficult to assess. In previous Mössbauer studies of papers impregnated with inks prepared by various recipes from ferrous sulfate and gallic acid, tannin or pyrogallol, mainly two components were found [30]. The dominant component is always a ferric quadrupole doublet with a splitting of about $0.8 \mathrm{~mm} / \mathrm{s}$ that resembles the doublet observed in the historical Manuscripts. The weaker component represents ferrous iron and has a quadrupole splitting of about $2.4 \mathrm{~mm} / \mathrm{s}$ at room temperature. In the present study of old Manuscripts the ferric component with a quadrupole splitting of about $0.8 \mathrm{~mm} / \mathrm{s}$ is also observed at room temperature. In the $4.2 \mathrm{~K}$ Mössbauer spectra, this component is still there, but part of 
it splits magnetically, presumably due to slow paramagnetic relaxation. In the Chancery $M S$, ferrous oxalate and jarosite were found, but the conditions under which these iron compounds form in inked papers still need to be clarified.

The un-inked papers of the three Manuscripts were found to contain at least ten times less iron than the inked parts. In these papers, most of the iron in the room temperature spectra is ferric and does not split magnetically. At $4.2 \mathrm{~K}$, part of it shows a magnetic splitting indicating the presence of goethite and perhaps lepidocrocite, but a ferric quadrupole doublet still remains. The nature of this doublet has yet to be explained. It might be similar to that observed in the inked papers.

The nature of the iron compound or compounds represented by the ferric quadrupole doublet found in the Manuscripts still requires clarification. It may represent more or less amorphous complexes of the iron with polyphenols other than the iron gallate considered as an essential pigment in the ink [31]. This ferric component may, however, also originate at least in part from reactions of the iron sulfate solution with cellulose within the paper, or from reactions of the iron with the binder of the ink. Since ferrogallic ink recipes often imply a large surplus of ferrous sulfate, the reaction products of this with the cellulose may even be a major constituent of the ferric iron in written Manuscripts.

\section{Acknowledgements \\ AL highly appreciates the opportunity to use the chemical laboratory of the Walther-Meißner-Institute given him by Prof. Dr. R. Gross. We thank Ms C. Beinhofer and Dr. T. Allscher, Institute for Book and Manuscript Restauration, Bavarian State Library, Munich, for valuable discussions, and Dr. A. Kölbl, Soil Science and Soil Protection, Martin Luther University Halle-Wittenberg, for providing the sample of potassium jarosite.}

\section{Authors' contributions}

AL designed and coordinated the practical and scientific work, was involved in the evaluation and interpretation of the data and wrote various drafts of the paper. FEW designed and coordinated the practical and scientific work, performed the Mössbauer spectroscopy, evaluated and interpreted the data and wrote the final version of the manuscript. MD carried out the $\mathrm{pH}$ measurements of the papers and determined the nature of the papers and gave valuable hints to research on historical documents. TE provided the fragments of the two Spanish documents. JLPP proposed this investigation and gave valuable hints on the documents. All authors read and approved the final manuscript.

\section{Funding}

Open Access funding enabled and organized by Projekt DEAL. There was no funding of the studies presented in this publication.

\section{Availability of data and materials}

The data sets used and/or analysed during the current study are available from the corresponding author on request.

\section{Declarations}

\section{Competing interests}

The authors declare that they have no competing interests.

\section{Author details}

${ }^{1}$ Walther-Meißner-Institute, Bavarian Academy of Sciences, Garching 85748, Germany. ${ }^{2}$ Physics Department, Technical University of Munich, 85748 Garching, Germany. ${ }^{3}$ Institute for Book and Manuscript Restauration, Bavarian State Library, 80539 München, Germany. ${ }^{4}$ Departamento de Pintura, Facultad de Bellas Artes, Universidad de Granada, Edificio Aynadamar, Avenida Andalucía s/n, 18071 Granada, Spain. ${ }^{5}$ Instituto de Ciencias de Materiales de Sevilla, Avda. Américo Vespucio S/N. Isla de La Cartuja, 41092 Sevilla, Spain.

Received: 26 October 2020 Accepted: 19 April 2021

Published online: 03 May 2021

\section{References}

1. Levey M. Some black inks in early mediaeval Jewish literature. Chymia. 1964;9:27-31.

2. Krekel C. Chemische Struktur historischer Eisengallustinten. In: Banik G, Weber $\mathrm{H}$, editors. Tintenfraßschäden und ihre Behandlung. Stuttgart: Kohlhammer; 1999. p. 25-220.

3. Reißland B. Neue Restaurierungsmethoden für Tintenfraß auf Papier mit wäßrigenPhythatlösungen - Möglichkeiten und Grenzen. In: Banik G, Weber $\mathrm{H}$, editors. Tintenfraßschäden und ihre Behandlung. Stuttgart: Kohlhammer; 1999. p. 113-220.

4. Zerdoun B-Y. Les Encres noires au Moyen-Âge (jusqu'à 1600). Paris: Éditions du Centre National de la Recherche Scientifique; 1983.

5. Aceto M, Agostino A, Boccaleri E, Garlanda AC. The Vercelli Gospels laid open: an investigation into the inks used to write the oldest Gospels in Latin. X-Ray Spectrom. 2008;37:286-92.

6. Ghigo T, Rabin I, Buzi P. Black Egyptian inks in Late Antiquity: new insights on their manufacture and use. Archaeol Anthropol Sci. 2020;12:70.

7. Martell P. Einige Beiträge zur Geschichte der Tinte. Z Angew Chem. 1913:26:197-9.

8. Banik G, Weber H, editors. Tintenfraßschäden und ihre Behandlung. Stuttgart Kohlhammer; 1999.

9. Kolar J, Strlič M, editors. Iron gall inks: on manufacture, characterization, degradation and stabilization. Ljubljana: National and University Library; 2006.

10. Agha-Aligol D, Khosravi F, Lameh-Rachti M, Baghizadeh A, Oliaiy P, Shokouhi F. Analysis of 18th-19th century's historical samples of Iranian ink and paper belonging to the Qajar dynasty. Appl Phys A. 2007;89:799-805.

11. Budnar M, Uršič M, Simčič J, Plicon P, Kolar J, Šelih VS, Strlič M. Analysis of iron gall inks by PIXE. Nucl Instrum Methods Phys Res B. 2006;243:407-16.

12. Kolar J, Štolfa A, Strlič M, Pompe M, Pihlar B, Budnar M, Simčič J, Reissland B. Historical iron gall ink containing documents- Properties affecting their condition. Anal Chim Acta. 2006;555:167-74.

13. Bicchieri M, Monti M, G Piantanida, Sodo A. Non-destructive spectroscopic investigation on historic Yemenite scriptorial fragments: evidence of different degradation and recipes for iron tannic inks. Anal Bioanal Chem. 2013. 405:2713-2721.

14. Bicchieri $M$, Monti M, Piantanida $G$, Sodo A. All that is iron-ink is not always iron-gall! J Raman Spectr. 2008;39:1074-8.

15. Diáz Hidalgo RJ, Córdoba R, Nabais P, Silva V, Melo MJ, Pina F, Teixeira N, Freitas V. New insights into iron-gall inks through the use of historically accurate reconstructions. Herit Sci. 2018;6:63.

16. Hahn O, Malzer W, Kanngießer B, Beckhoff B. Characterization of iron-gall inks in historical manuscripts and music compositions using $x$-ray fluorescence spectrometry. X-Ray Spectrom. 2004;33:234-9.

17. Kanngießer B, Hahn O, Wilke M, Nekat B, Malzer W, Erko A. Investigation of oxidation and migration processes of inorganic compounds in inkcorroded manuscripts. Spectrochim Acta B. 2004;59:1511-6.

18. Lee AS, Mahon PJ, Creagh DC. Raman analysis of iron gall inks on parchment. Vib Spectrosc. 2006;41:170-5.

19. Lee AS, Otieno-Alego V, Creagh DC. Identification of iron-gall inks with near-infrared and Raman microspectroscopy. J Raman Spectr. 2008:39:1079-84.

20. Wagner B, Bulska E, Stahl B, Heck M, Ornery HM. Analysis of Fe valence states in iron-gall inks from XVIth century manuscripts by ${ }^{57} \mathrm{Fe}$ Mössbauer spectroscopy. Anal Chim Acta. 2004;527:195-201. 
21. Proost K, Janssens K, Wagner B, Bulska E, Schreiner M. Determination of localized $\mathrm{Fe}^{2+} / \mathrm{Fe}^{3+}$ ratios in inks of historic documents by means of $\mu$-XANES. Nucl Instrum Methods Phys Res B. 2004;213:723-8.

22. Arčon I, Kolar J, Kodre A, Hanžel D, Strlič M. XANES analysis of Fe valence in iron gall inks. X-Ray Spectrom. 2007;36:199-205.

23. Wilke M, Hahn O, Woodland AB, Rickers K. The oxidation state of iron determined by Fe K-edge XANES — application to iron gall ink in historical manuscripts. J Anal At Spectrom. 2009;24:1364-72.

24. Danon J, Darbour M, Flieder F, Genand-Riondet N, Imbert P, Jehanno G, Roussel Y. Mössbauer study of ferro-gallic inks from manuscripts of the XIIth and the XVth centuries. Proc Indian Natl Sci Acad Part A: Special Volume; 1982. p. 841-3.

25. Darbour M, Onassis S, Fielder F. Les encres metallogalliques: etude de la degradation de l'acide gallique et analyse du complexe ferrogallique. Proc $6^{\text {th }}$ Triennial Meeting. Los Angeles: ICOM Committee for Conservation; 1981:Vol. III, 81/14/3, 1.

26. Dzinavatonga K, Bharuth-Ram K, Medupe TR. Mössbauer spectroscopy analysis of iron in historical documents obtained from the National Library of South Africa. J Cult Heritage. 2015;16:377-80.

27. Gütlich P, Bill E, Trautwein A, editors. Mössbauer Spectroscopy and Transition Metal Chemistry. Berlin-Heidelberg: Springer; 2011.

28. Murad E, Cashion J. Mössbauer Spectroscopy of Environmental Materials and their Industrial Utilization. Boston: Kluwer Academic Publishers; 2004.

29. Wagner FE, Lerf A. Mössbauer spectroscopic investigation of Fe(II) and Fe(III) gallate-proposed model compounds for iron-gall inks. Z Anorg Allg Chem. 2015;641:2384-91

30. Lerf A, Wagner FE. Model Compounds of Iron Gall Inks A Mössbauer Study. Hyperfine Interact. 2016;237:36.

31. Ponce A, Brostoff LB, Gibbons SK, Zavalji P, Viragh C, Hooper J, et al. Elucidation of the $\mathrm{Fe}(\mathrm{III})$ gallate structure in historical iron gall ink. Anal Chem. 2016;88:5152-68.

32. Burgaud C, Rouchon V, Refait P, Wattiaux A. Mössbauer spectrometry applied to the study of laboratory samples made of iron gall ink. Appl Phys A. 2008;92:257-62.

33. Jaén JA, De Obaldía J, Rodríguez MV. Application of Mössbauer spectroscopy to the study of tannins inhibition of iron and steel corrosion. Hyperfine Interact. 2011;202:25-38.

34. Jaén JA, González L, Vargas A, Olave G. Gallic acid, ellagic acid and pyrogallol reaction with metallic iron. Hyperfine Interact. 2003;148(149):227-35.

35. Iglesias J, García de Saldaña E, Jaén JA. On the tannic acid interaction with metallic iron. Hyperfine Interact. 2001;134:109-14.

36. Gust J, Suwalski J. Use of Mössbauer spectroscopy to study reaction products of polyphenols with iron compounds. Corrosion. 1994;50:355-65.

37. Hider RC, Mohd-Nor AR, Silver J, Morrison EG, Rees LVC. Model compounds for microbial iron transport compounds. Part 1. Solution chemistry and Mössbauer study of iron (II) and iron(III) complexes from phenolic and catecholic systems. J Chem Soc Dalton. 1981;609-622.

38. Burns RG. Mineral Mössbauer spectra: Correlation between chemical shift and quadrupole splitting parameters. Hyperfine Interact. 1994;91:739-45.

39. Wunderlich C-H, Weber R, Bergerhoff G. Über Eisengallustinte. Z Anorg Allg Chem. 1991;598(599):371-6.

40. Feller RK, Cheetham AK. Fe(III), Mn(III), Co(II), and Ni(II) 3.4.5-trihydroxybenzoate (gallate) dehydrates; a new family of hybrid framework materials. Solid State Sci. 2006:8:1121-5.

41. Driscoll RL, Leinz RW. Methods for synthesis of some jarosites. U. S. Geological Survey Techniques and Methods. 2005;5-D1:1-5.

42. Sturhahn W, Chumakov A. Lamb-Mössbauer factor and second order Doppler shift from inelastic nuclear resonance absorption. Hyperfine Interactions. 1999;123/124:809-824.

43. Jablonsky M, Dubinyová L, Varga Š, Visátová K, Šima J, Katuščák S. Cellulose fibre identification through color vectors of stained fibre. BioResources. 2015;10:5845-62.

44. De Grave E, Van Alboom A. Evaluation of ferrous and ferric Mössbauer fractions. Phys Chem Minerals. 1991;18:337-42.

45. Eckhout SG, De Grave E. Evaluation of ferrous and ferric Mössbauer fractions. Part II Phys Chem Minerals. 2003;30:142-6.

46. Attanasio D, Capitani D, Friederici C, Segre AL. Electron spin resonance study of paper samples dating from the fifteenth to the eighteenth century. Archaeometry. 1995;37:377-85.
47. Stephens CH, Barrett T, Whitmore PM, Wade JA, Mazurek J, Shilling M. Composition and condition of naturally aged papers. J Am Inst Cons. 2008;47:201-15.

48. Barrett T, Ormsby M. Land JB Non-destructive analysis of 14th-19th century European handmade papers. Restaurator. 2016;37(2):93-135.

49. Neevel JC, Reißland B. Bathophenanthroline Indicator Paper. PapierRestaurierung. 2005;6:28-36.

50. van der Zee C, Roberts DR, Rancourt DG, Slomp CPS. Nanogoethite is the dominant reactive oxyhydroxide in lake and maritime sediments. Geology. 2003;31:993-6.

51. Wagner FE, Wagner U, Häusler W, Costa BFO, Blot J-Y, Silva HJM, Bombico S. Mössbauer and XRD studies of Roman amphorae buried in the sea for twomillennia. Hyperfine Interact. 2016;237:57.

52. Kündig W. Evaluation of Mössbauer spectra for ${ }^{57} \mathrm{Fe}$. Nucl Instr Methods. 1967;48:219-28.

53. de Barros SF, Zory P, Campbell LE. The hyperfine structure of ${ }^{57} \mathrm{Fe}$ $\mathrm{FeC}_{2} \mathrm{O}_{4} \cdot 2 \mathrm{H}_{2} \mathrm{O}$. Phys Lett. 1963;7:135-6.

54. Ono K, Ito A. Mössbauer study of magnetic properties of ferrous compounds. J Phys Soc Jpn. 1964;19:899-907.

55. Bonville P, Dupuis V, Vincent E, Lippens PE, Wills AS. 57Fe Mössbauer spectra and magnetic data from the Kagomé antiferromagnet $\mathrm{H}_{3} \mathrm{O}$-jarosite. Hyperfine Interact. 2006;168:1085-9.

56. Afanasev AM, Gorobschenko VD, Kulgawczuk DS, Lukashevic II. Nuclear $Y$-resonance in iron sulfates of the jarosite group. Phys stat sol (a). 1974;26:697-701.

57. Dyar MB, Breves E, Jawin E, Marchand G, Nelms M, et al. Mössbauer parameters of iron in sulfate minerals. Amer Miner. 2013;98:1943-65.

58. Olowe AA, Génin JMR. Hyperfine structures of iron(II) sulphates: melanterite and rozenite. Hyperfinc Interact. 1991;68:253-6.

59. Van Alboom A, De Resende VG, De Grave E, Gómez JAM. Hyperfine interactions in szomolnokite ( $\mathrm{FeSO}_{4} \cdot \mathrm{H}_{2} \mathrm{O}$ ). J Mol Struct. 2009;924-926:448-56.

60. Johnson CE. Antiferromagnetism of $\mathrm{Y}$-FeOOH: A Mössbauer effect study. J Phys C (Sol St Phys). 1969;2:1996-2002.

61. De Grave E, Persoons RM, Chambaere DG, Vandenberghe RE, Bowen $\mathrm{LH}$. An57Fe Mössbauer effect study of poorly crystalline $\mathrm{\gamma}$-FeOOH. Phys Chem Minerals. 1986;13:61-7.

62. Mørup S. Magnetic relaxation phenomena. In: Gütlich P, Bill E, Trautwein A, editors. Mössbauer Spectroscopy and Transition Metal Chemistry. Berlin-Heidelberg: Springer; 2011. p. 211-34.

63. Funk F, Long GJ, Hautot D, Büchi R, Christl I, Weidler PG. Physical and chemical characterization of therapeutic iron containing materials: $A$ study of several superparamagnetic drug formulations with the $\beta-\mathrm{FeOOH}$ or ferrihydrite structure. Hyperfine Interact. 2001;136:73-95.

64. Eusterhues K, Wagner FE, Häusler W, Hanzlik M, Knicker H, Totsche KU, et al. Characterization of ferrihydrite-soil organic matter coprecipitates by X-ray diffraction and Mössbauer spectroscopy. Environ Sci Tech. 2008:42:7891-7.

65. Mikutta C, Mikutta R, Bonneville S, Wagner FE, Voegelin A, Christl I, Kretzschmar R. Synthetic coprecipitates of exopolysaccharides and ferrihydrite. Part I: Characterization. Geochim Cosmochim Acta. 2008;72:1111-27.

66. Majzlan J. Advances and gaps in the knowledge of thermodynamics and crystallography of acid mine drainage sulfate minerals. Chimia. 2010;64:699-704

67. Lee K, Inaba M. Moist heat accelerated aging test of naturally aged Paper by suspension method. Restaurator. 2013;34:81-100.

68. Calvini P, Silveira M. FTIR analysis of naturally aged $\mathrm{FeCl}_{3}$ and $\mathrm{CuCl}_{2}$-doped cellulose papers. e-Preservation Sci. 2008;5:1-8.

69. Ferrer F, Sistach MC. Characterization by FTIR spectroscopy of ink components in ancient manuscripts. Restaurator. 2005;26:105-17.

70. Ferrer $\mathrm{N}$, Sistach MC. Analysis of sediments on iron gall inks in manuscripts. Restaurator. 2013:34:175-93.

\section{Publisher's Note}

Springer Nature remains neutral with regard to jurisdictional claims in published maps and institutional affiliations. 